\title{
A WAVELET-BASED MULTIVARIABLE APPROACH FOR FAULT DETECTION IN DYNAMIC SYSTEMS
}

\author{
Henrique Mohallem Paiva* \\ henrique.paiva@embraer.com.br \\ Roberto Kawakami Harrop Galvão \\ kawakami@ita.br \\ Luis Rodrigues ${ }^{\ddagger}$ \\ luisrodeencs.concordia.ca \\ *Department of Flight Control Systems - Empresa Brasileira de Aeronáutica (EMBRAER) \\ São José dos Campos, SP, Brazil. \\ ${ }^{\dagger}$ Department of Electronic Engineering - Instituto Tecnológico de Aeronáutica (ITA) \\ São José dos Campos, SP, Brazil. \\ ${ }^{\ddagger}$ Department of Mechanical and Industrial Engineering - Concordia University, Montreal, QC, Canada.
}

\begin{abstract}
This paper presents a multivariable extension to a recently proposed wavelet-based technique for fault detection. In the original formulation, the Discrete Wavelet Transform is used to carry out dynamic consistency checks between pairs of signals within frequency subbands. For this purpose, moving average models with an integrative term are employed to reproduce the dynamics of the system in each subband under consideration. The present work introduces a new architecture allowing the use of subband models with more general multivariable structures. More specifically, a multivariable ARX (autoregressive with exogenous input) structure is adopted for each subband model. The proposed technique is illustrated in a case study involving a nonlinear simulation model for an aircraft with a sensor fault. The results show that the multivariable approach outperforms the original formulation in terms of residue amplification following the fault onset.
\end{abstract}

KEYWORDS: Dynamic Systems, Analytical Redundancy, Fault Detection, Wavelets, Multivariable Systems.

Artigo submetido em 11/02/2009 (Id.: 00949)

Revisado em 14/04/2009, 22/06/2009

Aceito sob recomendação do Editor Associado Prof. José Roberto Castilho Piqueira

\section{RESUMO}

Uma abordagem multivariável baseada em wavelets para detecção de falhas em sistemas dinâmicos

Este artigo apresenta uma extensão multivariável para uma técnica recentemente proposta de detecção de falhas baseada em wavelets. Na formulação original, a Transformada Wavelet Discreta é utilizada para realizar testes de consistência dinâmica entre pares de sinais dentro de faixas de freqüência. Para isso, são empregados modelos do tipo média móvel com termo integrativo para reproduzir a dinâmica do sistema em cada faixa considerada. O presente trabalho introduz uma nova arquitetura, que possibilita o uso de modelos em subbandas com estruturas multivariáveis mais gerais. Mais especificamente, uma estrutura ARX (autoregressiva com entrada exógena) multivariável é adotada para cada modelo em sub-bandas. A técnica proposta é ilustrada em um estudo de caso envolvendo um modelo de simulação não-linear para uma aeronave com falha de sensor. Os resultados mostram que a abordagem multivariável é superior à formulação original em termos de amplificação do resíduo após a ocorrência da falha.

PALAVRAS-CHAVE: Sistemas Dinâmicos, Redundância Analítica, Detecção de Falhas, Wavelets, Sistemas Multivariáveis. 
(a)

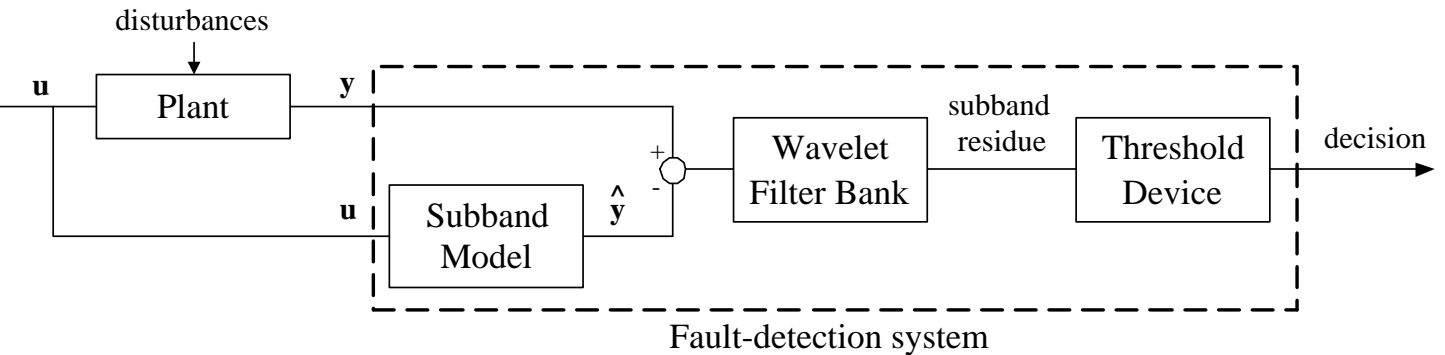

(b)

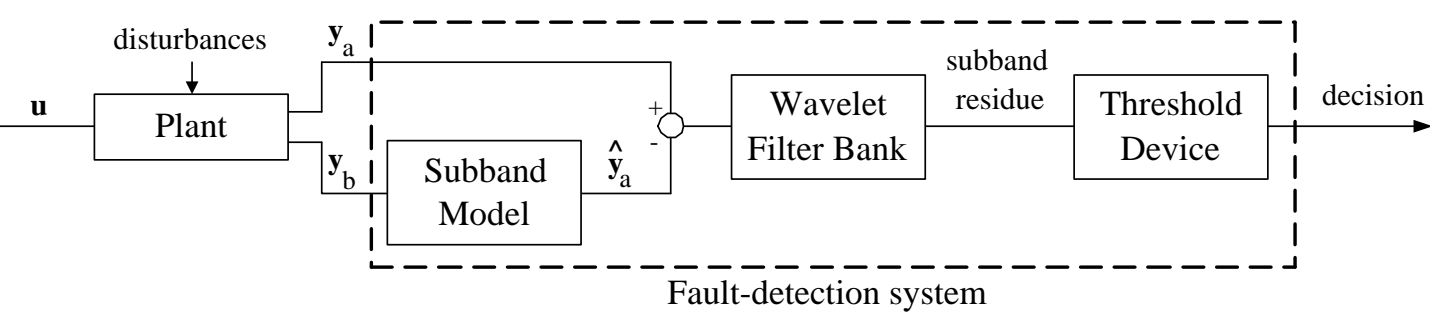

Figure 1: Original wavelet-based analytical redundancy architecture for (a) input-output and (b) output-output consistency checks. The subband model is of the form $\mathrm{M}(\mathrm{z})=\left(1-\mathrm{z}^{-1}\right)^{-s}\left(\alpha+\beta \mathrm{z}^{-1}\right), s \in \mathbb{Z} ; \alpha, \beta \in \mathbb{R}$.

\section{INTRODUCTION}

Prompt fault detection is essential for the improvement of reliability and dependability in complex control systems (Ranganathan et al., 2001), especially for safety-critical applications such as industrial plants (Kallesoe et al., 2006), chemical processes (Simani and Fantuzzi, 2006), automotive systems (Fischer et al., 2007) and aircraft (Amato et al., 2006), (Narasimhan and Biswas, 2007).

In this context, the Wavelet Transform (Daubechies, 1992) is a useful tool to detect transient behaviors caused by the onset of a fault. In (Bhunia and Roy, 2005), a wavelet-based strategy was employed to detect faults in digital CMOS circuits by transient current testing. For this purpose, wavelet coefficients of the current waveform were compared with coefficients obtained from a fault-free device. In (Zanardelli et al., 2005), the wavelet coefficients of a current signal were used in a classification framework to discriminate between different types of motor faults. In (Kim and Parlos, 2002), a dynamic neural network model was employed to predict the transient response of the system under monitoring. The residues thus generated were then processed by the wavelet transform to compute fault indicators. A combination of model-based residue generation and wavelet processing was also adopted in (Manders and Biswas, 2003), in which a temporal causal graph was employed to represent the normal behavior of the plant.

Most wavelet-related papers in the fault-detection literature exploit two basic approaches, namely: (a) decomposition of a sensor signal containing fault-related information (Zanardelli et al., 2005) or (b) decomposition of a residual signal calculated as the difference between the predictions of a model (or fault-free system) and the actual process output (Bhunia and Roy, 2005; Kim and Parlos, 2002; Manders and Biswas, 2003). A third approach, which was recently proposed in (Paiva, Galvão and Yoneyama, 2008), employs the wavelet transform to identify a subband model for the normal behavior of the system, which is then used to generate a residual signal. Such a formulation can be employed to monitor the input-output integrity of the plant (Fig. 1a) or the consistency between two plant outputs (Fig. 1b). A fault is indicated if the filtered difference between plant and model outputs exceeds a pre-defined threshold.

In (Paiva, Galvão and Yoneyama, 2008), this fault detection approach was favorably compared with a standard observerbased method in terms of sensitivity and false alarm ratio. However, the formulation was restricted to the analysis of pairwise consistency between dissimilar measurements. No provision was proposed for the simultaneous monitoring of more than two signals. Moreover, the case studies presented for illustration were restricted to linear, time-invariant systems. Aspects of robustness with respect to non-linearities or changes in the plant parameters were not investigated.

The present paper extends the technique proposed in (Paiva, Galvão and Yoneyama, 2008) to the multivariable case, in which several inputs and/or outputs are to be simultaneously checked for mutual consistency. For this purpose, the architecture adopted in (Paiva, Galvão and Yoneyama, 2008) is modified to allow the use of MIMO (multiple-input, multiple-output) system identification methods. In particular, a multivariable ARX (autoregressive with external input) 
(a)

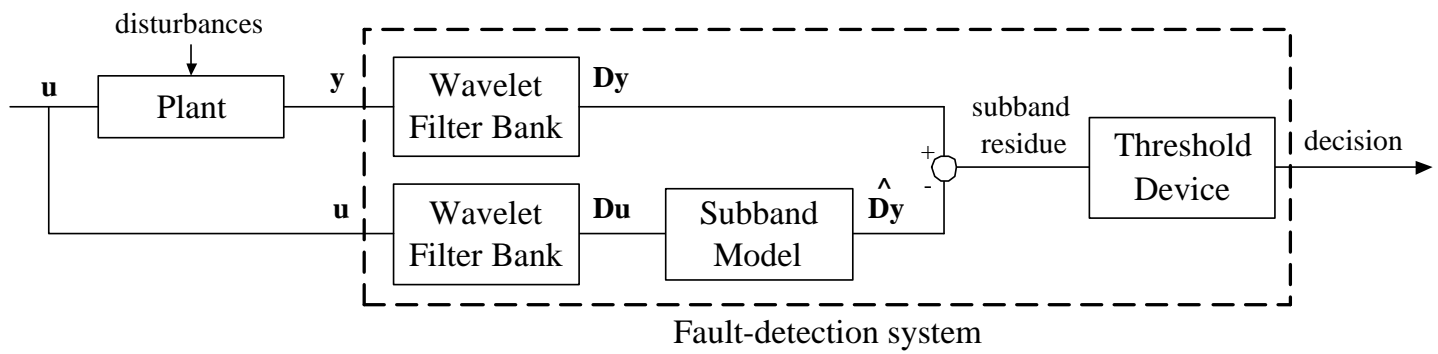

(b)

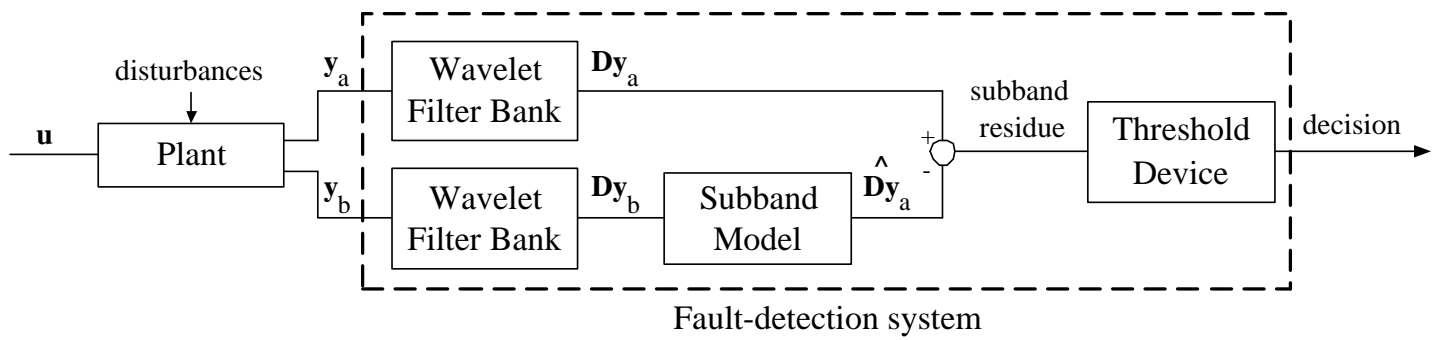

Figure 2: Frequency-Subband Analytical Redundancy Architecture adopted for the multivariable approach. (a) Input-output and (b) output-output consistency check.

structure is adopted for each subband model. Preliminary results obtained with this extension were reported in (Paiva, Galvão and Rodrigues, 2008), where a simplified example involving the linear model of a Boeing 747 aircraft was discussed. In the present work, the effectiveness of the extended technique is demonstrated in a case study involving the nonlinear aircraft simulation model ADMIRE (Forssell and Nilsson, 2005), which represents a generic small single-seat fighter aircraft with a delta-canard configuration. A sensor fault is considered for illustration. The fault detection performance is evaluated under the effect of model uncertainties, sensor dynamics, measurement noise and exogenous disturbances. The results of the proposed multivariable technique are compared with those obtained by using the original formulation presented in (Paiva, Galvão and Yoneyama, 2008).

\section{PROPOSED MULTIVARIABLE FAULT DETECTION TECHNIQUE}

In the SISO (single-input, single-output) architecture adopted in (Paiva, Galvão and Yoneyama, 2008) (Fig. 1), the subband model parameters $\alpha, \beta, s$ are adjusted in order to minimize the norm of the subband residue under normal operation conditions. However, standard identification techniques cannot be directly employed because the transmission path between the subband model input ( $\mathbf{u}$ in Fig. 1a or $\mathbf{y}_{\mathrm{b}}$ in Fig. 1b) and the subband residue involves the wavelet filter bank, which has to be taken into account. To circumvent this problem, an ad-hoc least-squares identification procedure was proposed in (Paiva, Galvão and Yoneyama, 2008). In the present paper, a different architecture (Fig. 2) is adopted in order to facilitate the extension to the MIMO case. In this new architecture, the subband model is placed after the wavelet filter bank.

The remaining of this section will be focused on the inputoutput scheme (Fig. 2a) for brevity. However, the discussion can be easily extended to the output-output scheme (Fig. 2b) by replacing plant input $\mathbf{u}$ and plant output $\mathbf{y}$ by plant outputs $\mathbf{y}_{\mathbf{b}}$ and $\mathbf{y}_{\mathbf{a}}$, respectively.

Fig. 3 shows a more detailed representation of the scheme presented in Fig. 2a. Filters $\mathrm{H}$ and $\mathrm{G}$ indicate the lowpass and highpass filters associated to a particular wavelet, respectively.

The choice of wavelet filters for a particular problem is still a matter of much research. Finite impulse response (FIR) filters, such as those of the Symlet (Zanardelli et al., 2005), Coiflet (Zanardelli et al., 2005) and specially Daubechies (Kim and Parlos, 2002), (Bhunia and Roy, 2005), (Paiva and Galvão, 2006), (Paiva, Galvão and Yoneyama, 2008), (Paiva, Galvão and Rodrigues, 2008), (Zanardelli et al., 2005) families, are usually employed in most applications. In general, longer filters have better frequency resolution, which improves the match between subband model and plant dynamics, as well as the rejection of noise. The drawback is the loss of time resolution, which causes larger detection delays. In previous papers (Paiva and Galvão, 2006), (Paiva, Galvão and Rodrigues, 2008), (Paiva, Galvão and Yoneyama, 2008), the $\mathrm{db} 8$ filters were found to provide a good tradeoff between noise rejection and time resolution. These filters will thus be adopted in the present work. 


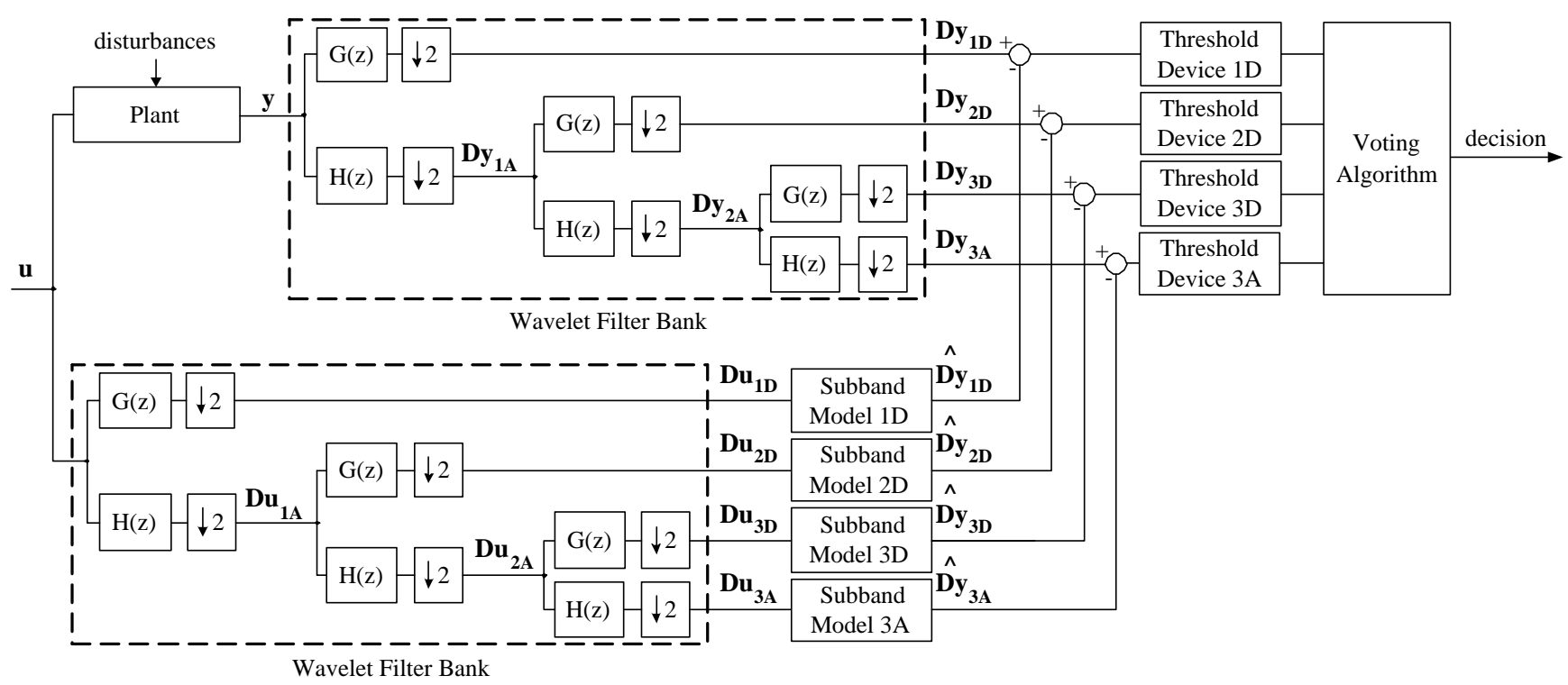

Figure 3: Wavelet-Based Frequency-Subband Analytical Redundancy Scheme

In the wavelet filter bank, the number of filtering iterations leading to a given layer is termed the decomposition level of that layer. In Fig. 3, for example, the filter bank has three decomposition levels. The best decomposition level for fault detection depends on the spectral signature of the fault, as well as the power spectrum density of the input signal and the signal-to-noise ratio of the measurements (Paiva, Galvão and Yoneyama, 2008). If the fault effect has not been previously characterized, all levels should be monitored simultaneously.

The outputs of the lowpass and highpass filters are termed approximation and detail, respectively. Subscripts $i \mathrm{~A}$ and $i \mathrm{D}$ will be used to indicate the approximation and detail at the $i$-th decomposition level, respectively. The wavelet coefficients $\mathbf{D} \mathbf{u}_{i \mathbf{A}}$ (approximation) and $\mathbf{D} \mathbf{u}_{i \mathbf{D}}$ (detail) of the input signal $\mathbf{u}$ at the $i$-th decomposition level, $i>0$, are calculated as

$$
\begin{aligned}
& \mathbf{D} \mathbf{u}_{i \mathbf{A}}=(\downarrow 2)\left[h * \mathbf{D} \mathbf{u}_{(i-1) \mathbf{A}}\right] \\
& \mathbf{D} \mathbf{u}_{i \mathbf{D}}=(\downarrow 2)\left[g * \mathbf{D} \mathbf{u}_{(i-1) \mathbf{A}}\right]
\end{aligned}
$$

where $(\downarrow 2)$ and $*$ denote the downsampling and convolution operations, and $h$ and $g$ are the discrete-time impulse responses of filters $\mathrm{H}$ and $\mathrm{G}$, respectively. The approximation $\mathbf{D} \mathbf{u}_{0 \mathbf{A}}$ at level 0 is equal to signal $\mathbf{u}$ itself. Similar equations can be used to obtain the wavelet coefficients $\mathbf{D y}_{i \mathbf{A}}$ (approximation) and $\mathbf{D y}_{i \mathbf{D}}$ (detail) of the output signal $\mathbf{y}$.

The configuration adopted for each subband model in Fig. 3 is a multivariable ARX (autoregressive with exogenous in- put) structure of the form (Ljung, 1999):

$$
\begin{gathered}
\hat{\mathbf{D y}}(k)=\sum_{i=1}^{n_{a}} A_{i} \hat{\mathbf{D y}}(k-i)+\sum_{i=1}^{n_{b}} B_{i} \mathbf{D u}(k-i), \\
A_{i} \in \mathbb{R}^{p \times p}, B_{i} \in \mathbb{R}^{p \times m}
\end{gathered}
$$

where $\mathbf{D u}(k) \in \mathbb{R}^{m}$ and $\hat{\mathbf{D y}}(k) \in \mathbb{R}^{p}$ correspond to the input and output of the subband model at time index $k$. Since each subband model is intended to represent the plant behavior only within a limited frequency band, the orders $n_{a}$ and $n_{b}$ can be made small. Matrices $A_{i}, B_{i}$ can be identified in order to minimize the 2-norm of the difference between the model predictions $\hat{\mathbf{D y}}$ and the wavelet coefficients Dy of the actual plant output. For this purpose, a standard multivariable least-squares identification method can be employed (Ljung, 1999).

After the identification has been carried out, the threshold for each subband detector can be established on the basis of the subband residue (Dy $-\hat{\mathbf{D y}}$ ) obtained for nominal (faultfree) conditions. In this work, the threshold is set to three times the standard deviation of the residue calculated by using signals $\mathbf{u}, \mathbf{y}$ different from those employed for identification.

As shown in Fig. 3, the system is monitored over different frequency subbands. The information of all threshold devices is submitted to a voting algorithm that determines whether the overall fault monitor will indicate a fault or not. The simultaneous monitoring of several frequency subbands is important because the fault effect may be more noticeable in some bands, which can vary according to the 
system under study and the fault effect (Paiva, Galvão and Yoneyama, 2008). In the present work, the overall fault monitor declares a fault if any threshold detector is activated.

It is worth noting that time resolution decreases as the decomposition is carried out from one level to the next. As a result, longer detection delays may be expected at the final levels of the filter bank. This feature may impose a restriction on the maximum number of resolution levels that can be employed in the fault monitor.

\section{Summary}

In what follows, the algorithm to construct the fault-detection structure presented in Fig. 3 is shortly summarized.

1. Collect signals $\mathbf{u}$ and $\mathbf{y}$ to perform the identification of the subband models.

2. Choose wavelet filters $H$ and $G$ and the number of decomposition levels of the wavelet tree.

3. Calculate the wavelet coefficients Du and Dy at each decomposition level.

4. Use an ARX identification procedure (Ljung, 1999) to identify the subband model matrices in Eq. (3).

5. Collect new signals $\mathbf{u}$ and $\mathbf{y}$ to establish the thresholds.

6. Calculate, at each decomposition level, the wavelet coefficients Du and Dy of the new signals, and obtain the corresponding subband model output $\hat{\mathbf{D y}}$.

7. Establish the thresholds as a function of the residue (Dy - $\hat{\mathbf{D y}})$.

The ARX model order could be selected by using techniques such as Akaike's information theoretic criterion (AIC) (Ljung, 1999), Rissanen's minimum description length (MDL) principle (Ljung, 1999) or generalized crossvalidation (GCV) (Sjöberg et al., 1995), (Paiva and Galvão, 2006). Alternatively, the order may be increased, starting from a small value, until the fault detection performance is deemed acceptable. It is worth noting that, as the identification only concerns the system dynamics within a restricted frequency range, the subband model order can be small as compared to a time-domain ARX representation.

As a general rule, the thresholds should be set to the smallest values that still result in a satisfactory false alarm rate, according to the requirements of the application at hand. If faulty data were available, the thresholds could be chosen to achieve an appropriate trade-off between fault detection and false alarm rates.

\section{APPLICATION EXAMPLE}

In this section, a case study involving the nonlinear aircraft simulation model ADMIRE (Aero-Data Model In a Research Environment) will be presented.

\subsection{System Description}

ADMIRE is a generic model of a small single-seat fighter aircraft with a delta-canard configuration. The model is augmented with longitudinal and lateral flight control systems to provide stability and handling qualities and contains a rudimentary speed controller. The model envelope extends up to Mach 1.2 and altitude of $6 \mathrm{~km}$. A detailed description of this model, as well as the electronic files required for simulation, can be found in (Forssell and Nilsson, 2005).

In the present study, turbulence and wind gust models were incorporated in the simulation. The turbulence models follow the Dryden form (U.S. Military Specification MIL-F$8785 \mathrm{C}, 1980)$. The turbulence scale lengths, turbulence intensities, and gust magnitude were adopted according to (U.S. Military Specification MIL-F-8785C, 1980) in order to simulate light, moderate and severe atmospheric disturbances, as shown in Table 1.

Table 1: Atmospheric disturbance parameters.

\begin{tabular}{cccc}
\hline \hline Severity & Light & Moderate & Severe \\
\hline $\begin{array}{c}\text { Turbulence } \\
\text { Scale Length }(\mathrm{ft}) \\
\left(L_{u}=L_{v}=L_{w}\right)\end{array}$ & 1750 & 1750 & 1750 \\
\hline $\begin{array}{c}\text { Turbulence } \\
\text { Intensity }(\mathrm{ft} / \mathrm{s})\end{array}$ & 5 & 15 & 25 \\
$\left(\sigma_{u}=\sigma_{v}=\sigma_{w}\right)$ & & & \\
\hline $\begin{array}{c}\text { Gust } \\
\text { Magnitude } \\
(\mathrm{ft} / \mathrm{s})\end{array}$ & 16.7 & 33.3 & 50 \\
\hline \hline
\end{tabular}

ADMIRE contains dynamic models of the rate gyros responsible for measuring the body-fixed roll-rate $p_{b}$, pitch rate $q_{b}$ and yaw-rate $r_{b}$. In this study, zero-mean white noise with standard deviation of $0.2 \mathrm{deg} / \mathrm{s}$ was added to the output of each rate gyro. This noise level is realistic for aeronautical sensors, as discussed in (Bacon et al., 2001).

\subsection{Simulations}

The following sets of simulations were conducted:

- Model Identification 
A set of fault-free simulations was carried out to identify the subband system models. In each simulation, the aircraft was initially trimmed at straight level. Since the dynamic response of the aircraft varies with the velocity and altitude of operation, twelve points in the envelope (three velocities versus four altitudes) were chosen for trimming: Mach 0.6, 0.9 and 1.2; altitude of 3, 4, 5 and $6 \mathrm{~km}$. For each point, the system was simulated during $20 \mathrm{~s}$ under light atmospheric disturbance. In order to enrich the spectral content of the excitation signals, small slow-varying augmentation commands were added to the rudder and canard commands generated by the control law. Such augmentation commands consist of a zero-mean square wave with peak-to-peak amplitude of 2.8 deg and frequency of $0.5 \mathrm{~Hz}$. Fig. 4 shows, for a particular simulation, the total rudder and canard commands, as well as the angular rates.

\section{- Threshold definition}

A second set of twelve fault-free simulations (one for each point of the envelope) was carried out to establish the threshold for each detector. The simulation conditions were similar to those employed in the identification phase, but with different realizations of atmospheric disturbance and sensor noise.

\section{- Fault simulations}

The fault detection problem consisted of detecting a bias of $1.0 \mathrm{deg} / \mathrm{s}$ in the yaw rate $\left(r_{b}\right)$ gyro. The bias was inserted at $\mathrm{t}$ $=20 \mathrm{~s}$ in a simulation lasting $40 \mathrm{~s}$. Three different cases were considered:

Case 1 - Straight level: The aircraft was trimmed in straight level at the twelve envelope points specified above. In order to illustrate the robustness of the technique to exogenous disturbances, three simulations were carried out for each point, considering different atmospheric disturbance levels (light, moderate and severe). Therefore, a total of 36 simulations were performed. Fig. 5 shows the angular rates obtained in a particular simulation. As can be seen, the fault in the $r_{b}$ sensor also induced a change in the behavior of $p_{b}$. Such a coupling effect is caused by the closed-loop control system.

Case 2 - Straight level with uncertainties: In order to illustrate the robustness of the technique to model uncertainties, the system was simulated considering the mass, inertia and center of gravity (CG) uncertainties specified in Table 2. These are the maximum uncertainties that can be used with the ADMIRE model (Forssell and Nilsson, 2005). Each of the 36 simulations described in Case 1 was repeated twice: first with the positive uncertainties in Table 2, and then with the negative ones. Therefore, a total of 72 simulations were carried out.

Case 3 - Altitude Change: In this case, the fault detection per-
Table 2: ADMIRE uncertainty parameters.

\begin{tabular}{ccc}
\hline \hline Parameter & & Uncertainty \\
\hline Inertia & Ixx & $\pm 20 \%$ \\
& Iyy & $\pm 5 \%$ \\
& $I z z$ & $\pm 8 \%$ \\
& $I x z$ & $\pm 15 \%$ \\
Mass & $M$ & $\pm 20 \%$ \\
CG Position & $x_{C G}$ & $\pm 0.15 \mathrm{~m}$ \\
& $y_{C G}$ & $\pm 0.1 \mathrm{~m}$ \\
\hline \hline
\end{tabular}

formance was evaluated during an altitude change manoeuver, rather than in straight flight. The airplane was initially trimmed at Mach 1, altitude of $6 \mathrm{~km}$, and then descended to an altitude of $4 \mathrm{~km}$. The system was simulated under light, moderate and severe atmospheric disturbance.
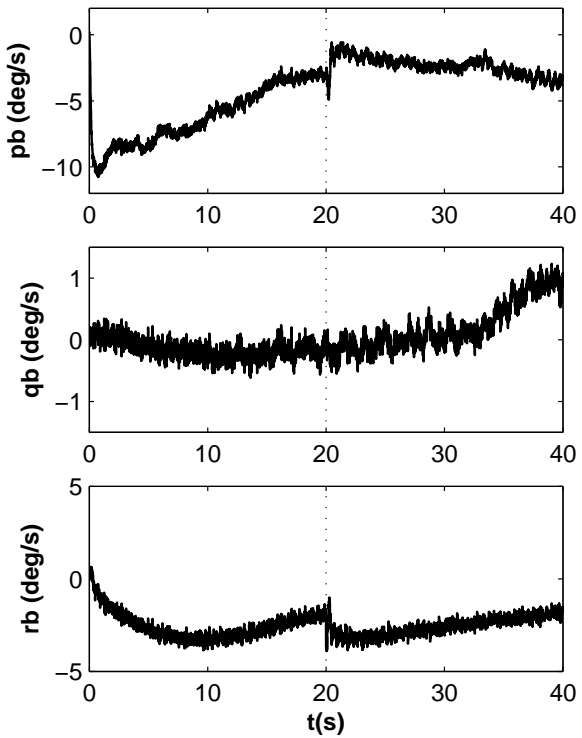

Figure 5: Angular rates obtained in one of the fault simulations. In this particular simulation, the aircraft was trimmed at Mach 0.9 and altitude of $6 \mathrm{~km}$, and was subjected to moderate atmospheric disturbance. 

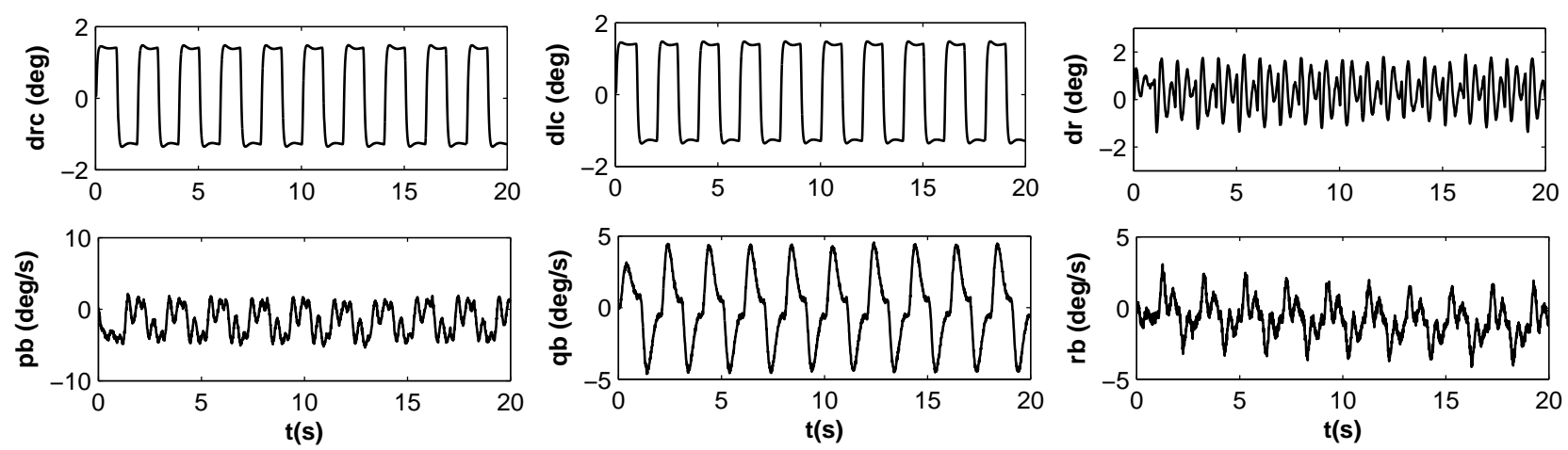

Figure 4: Angular rates and canard/rudder commands obtained in one of the simulations used for identification. drc, dlc and $\mathrm{dr}$ denote the total commands for the right canard, left canard and rudder, respectively. In this particular simulation, the aircraft was trimmed at Mach 0.9 and altitude of $6 \mathrm{~km}$, and was subjected to light atmospheric disturbance.
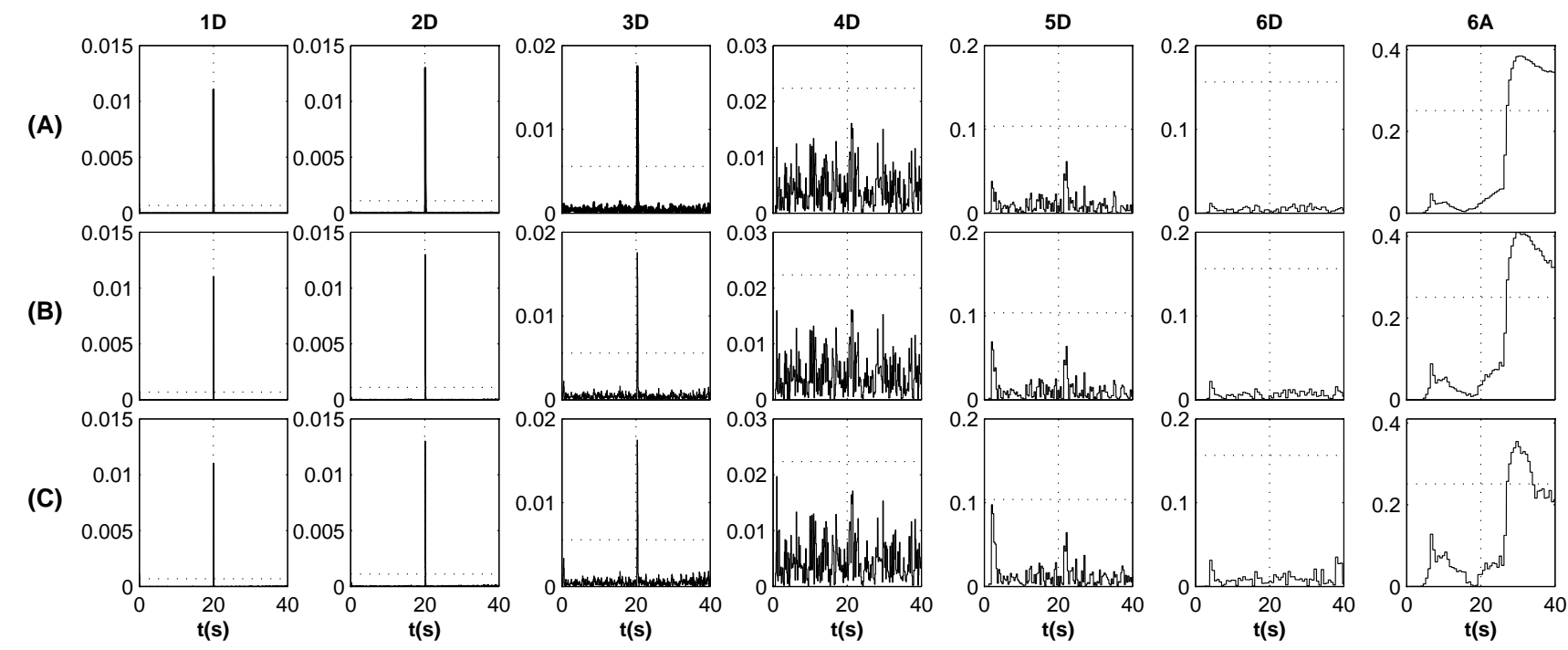

Figure 6: Subband residues for the details at decomposition levels 1 to 6 (indicated as 1D to 6D) and approximation at decomposition level 6 (indicated as 6A). In this particular simulation, the aircraft was trimmed at Mach 0.9 and altitude of 6 $\mathrm{km}$, and was subjected to (A) light, (B) moderate and (C) severe atmospheric disturbance.

\subsection{Fault detection results}

The fault detection results obtained with the original formulation proposed in (Paiva, Galvão and Yoneyama, 2008) and the extended multivariable formulation presented in this paper will now be compared. The original formulation was employed to check the consistency between sensors $\left(p_{b}, r_{b}\right)$ and $\left(q_{b}, r_{b}\right)$. In this case, signal $\mathbf{y}_{\mathbf{a}}$ in Fig. $1 \mathrm{~b}$ corresponds to $r_{b}$, and $\mathbf{y}_{\mathbf{b}}$ corresponds to either $p_{b}$ or $q_{b}$. In the extended approach, the consistency between sensors $\left(p_{b}, q_{b}\right)$ and $r_{b}$ was evaluated. In this case, signal $\mathbf{y}_{\mathbf{a}}$ in Fig. $2 \mathrm{~b}$ corresponds to $r_{b}$ and $\mathbf{y}_{\mathbf{b}}$ corresponds to vector $\left[p_{b} q_{b}\right]^{T}$. Six decomposition levels were used in the wavelet filter banks. The ARX orders $n_{a}=1$ and $n_{b}=2$ were adopted for each subband model.

As a result, all faults were correctly detected, that is, at least one subband residue exceeded the threshold for fault detection after the fault onset, and no subband residue exceeded the threshold before the fault. The time for detection was always less than $0.1 \mathrm{~s}$. Such a delay may be considered acceptable in view of the response speed of the system (the peak time for the yaw rate following a 1 deg step in the rudder command varies from $1.4 \mathrm{~s}$ to $2.0 \mathrm{~s}$, depending on the flight condition). 
For illustration, Fig. 6 shows the residues obtained using the multivariable technique for a particular fault simulation. In this figure, the horizontal dashed lines indicate the threshold for fault detection, and the vertical dashed lines indicate the fault onset at $t=20 \mathrm{~s}$. This figure shows that the fault under study causes an almost immediate response in the residues associated to the higher frequencies (1D, 2D and 3D), which rise and then fall shortly after. On the other hand, the residue associated to the lower frequencies (6A) responds to the fault after a delay, but is kept on a high level afterwards. The figure also shows that the residue tends to increase with the atmospheric disturbance (especially at levels 5D and 6A), but does not exceed the threshold before the fault onset.

In order to clarify the advantage of the multivariable formulation over the original approach, the following metric $\Gamma$ was evaluated (Paiva, Galvão and Yoneyama, 2008):

$$
\begin{aligned}
\Gamma & =\frac{\max _{\mathrm{t}}\left(\operatorname{abs}\left(\text { residue }_{\text {after_fault }}\right)\right)}{\max _{\mathrm{t}}(\operatorname{abs}(\text { residue } \text { before_fault }))} \\
& =\frac{\max _{\mathrm{t} \in(20,40 \mathrm{~s}]}(\text { abs }(\text { residue }))}{\max _{\mathrm{t} \in[0 \mathrm{~s}, 20 \mathrm{~s}]}(\operatorname{abs}(\text { residue }))}
\end{aligned}
$$

The definition above applies to the residue at each decomposition level. For the overall fault monitor, the value of $\Gamma$ is defined as the maximum value obtained over all decomposition levels. This index is calculated offline (that is, after the simulation is carried out) and reflects the sensitivity of the detector with respect to the fault effects. The larger the $\Gamma$, the larger the probability of correctly detecting a fault for a fixed false alarm ratio. Therefore, index $\Gamma$ can be used as a metric to compare different fault detection methods, as discussed in (Paiva, Galvão and Yoneyama, 2008).

Table 3 presents the values of $\Gamma$ (average and standard deviation) obtained in the three fault-detection cases, which together comprised 111 simulations. As can be seen, the largest values of $\Gamma$ were always obtained with the multivariable approach. A comparison between cases 1, 2 and 3 reveals that both model uncertainties and variations in the flight condition tend to reduce the value of $\Gamma$. Nevertheless, the result remains satisfactory, as the monitor was always able to detect the fault with no false alarms.

Table 3: After-fault residue amplification $\Gamma$.

\begin{tabular}{lccc}
\hline \hline & $\begin{array}{c}\text { Multivariable } \\
\left(p_{b}, q_{b}\right) \text { to }\left(r_{b}\right)\end{array}$ & $\begin{array}{c}\text { Original } \\
p_{b} \text { to } r_{b}\end{array}$ & $\begin{array}{c}\text { Original } \\
q_{b} \text { to } r_{b}\end{array}$ \\
\hline Case 1 & $29.4 \pm 8.1$ & $12.8 \pm 3.0$ & $13.3 \pm 1.5$ \\
Case 2 & $28.0 \pm 9.9$ & $11.8 \pm 3.9$ & $12.0 \pm 1.4$ \\
Case 3 & $27.7 \pm 8.1$ & $10.5 \pm 2.7$ & $10.4 \pm 1.5$ \\
\hline \hline
\end{tabular}
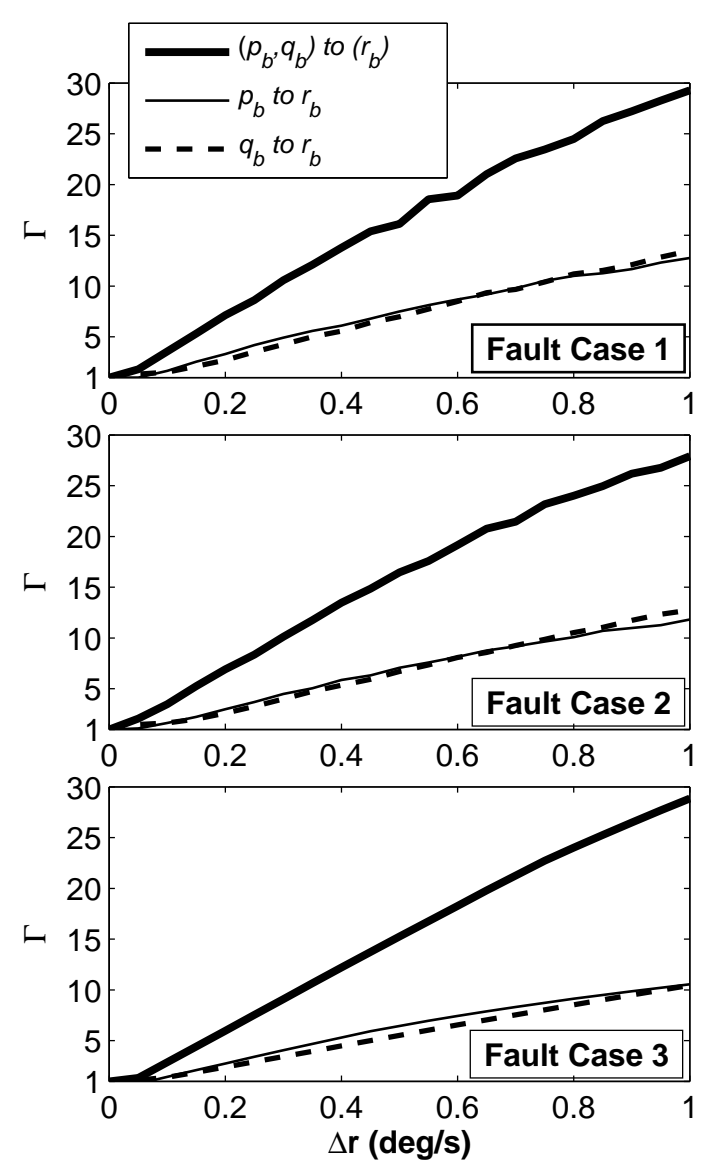

Figure 7: $\Gamma$ values for faults of different magnitudes.

Finally, Figure 7 presents a comparative evaluation of the fault monitors for faults of different magnitudes (i.e. different values of bias added to the yaw rate gyro). As can be seen, the values of $\Gamma$ for the multivariable approach $\left(\left(p_{b}, q_{b}\right)\right.$ to $r_{b}$ ) are always larger as compared to those obtained with the original formulation ( $p_{b}$ to $r_{b}$ and $q_{b}$ to $r_{b}$ ).

\section{CONCLUSIONS}

This paper extended a recent wavelet-based fault detection method to the multivariable case, in which more than two signals can be simultaneously checked for mutual consistency. In the proposed technique, consistency checks are performed within frequency bands established by a wavelet filter bank. Subband models are identified at each specified frequency band. A new architecture was proposed, allowing the use of a general structure for the subband models and the use of standard identification techniques to identify their parameters. An ARX structure was adopted for each subband model. 
with a simulated sensor fault was presented. Fault detection was carried out by checking the mutual dynamic consistency of three different sensor signals. The results indicate that the proposed technique can provide high standards of reliability. In fact, the fault was successfully detected in all simulations and no false alarm occurred, even in the presence of nonlinearities, model uncertainties, measurement noise, sensor dynamics, altitude change commands and exogenous disturbances. An analysis of the residues in normal and faulty conditions also revealed an improvement in sensitivity with respect to the previous formulation, in which the sensors are compared in a pairwise manner. If necessary, robustness against false alarm sources could be further improved by declaring a fault only if the residue exceeds the threshold at more than one frequency subband. In addition, the technique could be used together with standard approaches such as those based on state observers.

Future studies could circumvent the restriction of constant relative bandwidth of the wavelet filter bank by using wavelet packets, which yield more general frequency partitions, as adopted in (Paiva and Galvão, 2006). Furthermore, the choice of the wavelet filters could be addressed by using adaptive wavelets (Paiva et al., 2009). Moreover, improvements in the wavelet fault monitor might possibly be achieved by using subband models with different structures. With the general architecture proposed in this paper, modifications in the structure of the subband models can be easily implemented. Finally, future works could be concerned with the problem of fault isolation, which has not been addressed in the present paper.

\section{ACKNOWLEDGEMENTS}

This work was supported by Canadian agencies NSERC and FQRNT, by Brazilian agencies CNPq (research fellowship and post-doctoral grant 200721/2006-2) and FAPESP (grant 2006/58850-6), and by EMBRAER. The contributions of Dr. Fernando Jose de Oliveira Moreira, Dr. Narendra Gollu and Mr. Alvaro Vitor Polati de Souza, concerning possible applications of the technique and discussions about system identifications techniques, are gratefully acknowledged. The authors also wish to thank the developers of ADMIRE at the Swedish Defense Research Agency for making this model available for research purposes.

\section{REFERENCES}

Amato, F., Cosentino, C., Mattei, M. and Paviglianiti, G. (2006). A direct/functional redundancy scheme for fault detection and isolation on an aircraft, Aerospace Science and Technology 10(4): 338-345.

Bacon, B. J., Ostroff, A. J. and Joshi, S. M. (2001). Re- configurable NDI controller using inertial sensor failure detection and isolation, IEEE Trans. Aerospace and Electronic Systems 37(4): 1373-1383.

Bhunia, S. and Roy, K. (2005). A novel wavelet transformbased transient current analysis for fault detection and localization, IEEE Trans. Very Large Scale Integration (VLSI) Systems 13(4): 503-507.

Daubechies, I. (1992). Ten Lectures on Wavelets, CBMSNSF Series in Applied Mathematics number 61, SIAM, Philadelphia, Pennsylvania.

Fischer, D., Borner, M., Schmitt, J. and Isermann, R. (2007). Fault detection for lateral and vertical vehicle dynamics, Control Engineering Practice 15(3): 315-324.

Forssell, L. and Nilsson, U. (2005). ADMIRE The AeroData Model In a Research Environment Version 4.0, Model Description, Report FOI-R-1624-SE, ISSN 1650-1942, Swedish Defence Research Agency, Available at www.foi.se/admire.

Kallesoe, C. S., Cocquempot, V. and Izadi-Zamanabadi, R. (2006). Model based fault detection in a centrifugal pump application, IEEE Trans. Control Systems Technology 14(2): 204-215.

Kim, K. and Parlos, A. G. (2002). Induction motor fault diagnosis based on neuropredictors and wavelet signal processing, IEEE/ASME Trans. Mechatronics 7(2): 201219.

Ljung, L. (1999). System Identification: Theory for the User, 2nd edn, Prentice Hall, Upper Siddle River, New Jersey.

Manders, E. J. and Biswas, G. (2003). FDI of abrupt faults with combined statistical detection and estimation and qualitative fault isolation, Proc. 5th Symposium on Fault Detection, Supervision and Safety for Technical Processes, Washington, DC, pp. 347-352.

Narasimhan, S. and Biswas, G. (2007). Model-based diagnosis of hybrid systems, IEEE Trans. Systems, Man and Cybernetics - Part A: Systems and Humans 37(3): 348361 .

Paiva, H. M. and Galvão, R. K. H. (2006). Wavelet-packet identification of dynamic systems in frequency subbands, Signal Processing. 86(8): 2001-2008.

Paiva, H. M., Galvão, R. K. H. and Rodrigues, L. (2008). Redundância analítica multivariável em sub-bandas de freqüência utilizando decomposição wavelet, 17 o Congresso Brasileiro de Automática, paper 37579, Sociedade Brasileira de Automática, Juiz de Fora, MG. 
Paiva, H. M., Galvão, R. K. H. and Yoneyama, T. (2008). A wavelet band-limiting filter approach for fault detection in dynamic systems, IEEE Trans. Systems, Man and Cybernetics - Part A: Systems and Humans 38(3): 680-687.

Paiva, H. M., Martins, M. N., Galvão, R. K. H. and Paiva, J. P. L. M. (2009). On the space of orthonormal wavelets: Additional constraints to ensure two vanishing moments, IEEE Signal Processing Letters 16: 101-104.

Ranganathan, N., Patel, M. I. and Sathyamurthy, R. (2001). An intelligent system for failure detection and control in an autonomous underwater vehicle, IEEE Trans. Systems, Man and Cybernetics - Part A: Systems and Humans 31(6): 762-767.

Simani, S. and Fantuzzi, C. (2006). Dynamic system identification and model-based fault diagnosis of an industrial gas turbine prototype, Mechatronics 16: 341-363.

Sjöberg, J., Zhang, Q., Ljung, L., Benveniste, A., Deylon, B., Glorennec, P.-Y., Hjalmarsson, H. and Juditsky, A. (1995). Nonlinear black-box modeling in system identification: A unified overview, Automatica 31(12): 1691-1724.

U.S. Military Specification MIL-F-8785C (1980). Flying Qualities of Piloted Airplanes.

Zanardelli, W. G., Strangas, E. G., Khalil, H. K. and Miller, J. M. (2005). Wavelet-based methods for the prognosis of mechanical and electrical failures in electric motors, Mechanical Systems and Signal Processing 19(2): 411426. 